\title{
Effect of artificial accelerated aging on surface roughness and color stability of different ceramic restorations
}

\author{
Tamer A. Hamza'1, Ahmed A. Alameldin², Ahmed Y. Elkouedi², Alvin G. Wee ${ }^{3}$ \\ ${ }^{I}$ Department of Fixed Prosthodontics, Faculty of Oral and Dental Medicine, Misr International University, Cairo 11828, Egypt. \\ ${ }^{2}$ Department of Fixed Prosthodontics, Faculty of Oral and Dental Medicine, Al-Azher University, Cairo 11762, Egypt. \\ ${ }^{3}$ Dental Service, Staff Maxillofacial Prosthodontist, VA Nebraska-Western Iowa Healthcare System, Department of Prosthodontics, Creighton University \\ School of Dentistry, Omaha, NE 68178, USA.
}

Correspondence to: Dr. Tamer A. Hamza, Department of Fixed Prosthodontics, Faculty of Oral and Dental Medicine, Misr International University, Cairo 11828, Egypt. E-mail: drtamerhamza@hotmail.com

How to cite this article: Hamza TA, Alameldin AA, Elkouedi AY, Wee AG. Effect of artificial accelerated aging on surface roughness and color stability of different ceramic restorations. Stomatological Dis Sci 2017;1:8-13.

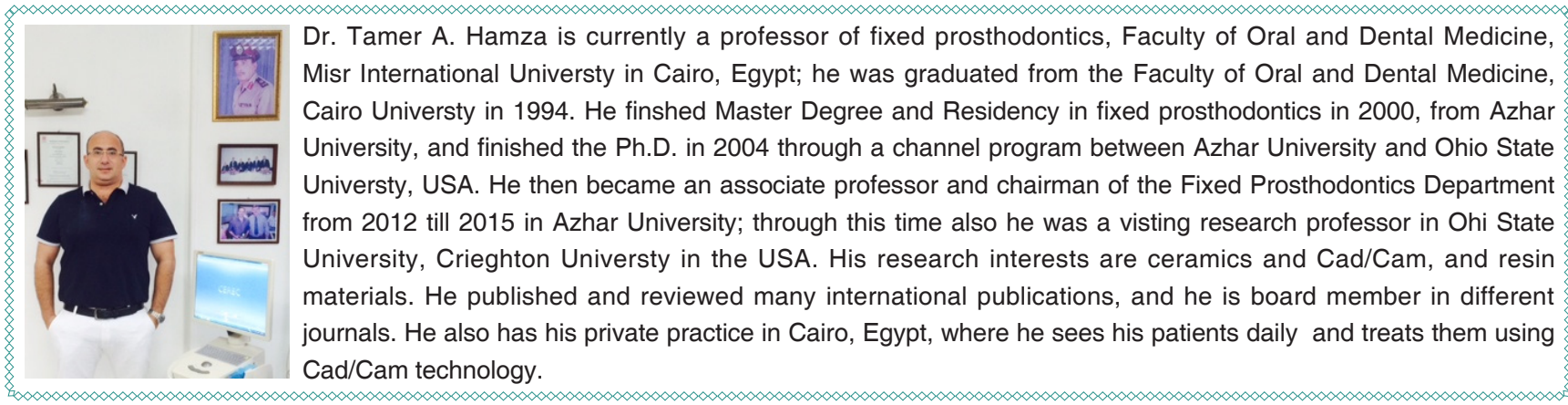

Article history:

Received: 09-08-2016

Accepted: 21-09-2016

Published: 31-03-2017

Key words:

Accelerated aging,

dental ceramics,

color stability,

surface roughness

\begin{abstract}
Aim: The purpose of the study was to evaluate the effect of artificial accelerated aging on surface roughness and color stability of three recently introduced CAD/CAM materials. The hypothesis was that artificial accelerated aging would have an effect on surface roughness and color stability of tested materials. Methods: A total of 21 ceramic discs were fabricated in this study, including translucent zirconia (InCoris TZI) and resin nano ceramic (Lava Ultimate) ceramic blocks for CAD/CAM and a set of bi-layered discs made of a zirconia CAD/CAM substructure (inCoris ZI) with VM9 hand-layered feldspathic veneering. Initial surface roughness measurements using a stylus profilometer and color measurements using a spectroradiometer were carried out. All specimens were subjected to artificial aging by means of a weathering process in a Weather-O-meter for $300 \mathrm{~h}$. Additional surface roughness
\end{abstract}

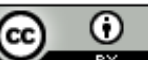

This is an open access article licensed under the terms of Creative Commons Attribution 4.0 International License (https://creativecommons.org/licenses/by/4.0/), which permits unrestricted use, distribution, and reproduction in any medium, as long as the original author is credited and the new creations are licensed under the identical terms.

For reprints contact: service@oaepublish.com

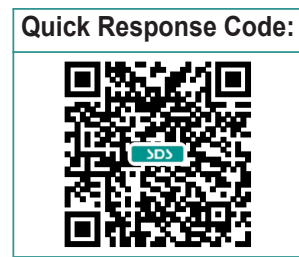


and color measurements were again carried out after artificial aging of the specimens. The Wilcoxon Signed Rank Test was conducted to determine significant differences in surface roughness among the 3 groups $(\alpha=0.05)$. Results: Lava ultimate specimens showed a statistically significant difference in surface roughness before and after artificial accelerated aging $(P=0.028)$. There was no statistical significance in surface roughness of both the translucent zirconia TZ1 $(P=0.499)$ and the InCoris ZI with VM9 veneering $(P=0.398)$ specimens before and after aging. The amount of color change in the 3 ceramic groups was also not significant. Conclusion: Artificial accelerated aging did not affect the color stability of any of the 3 ceramic groups, however, it caused a significant decrease in the surface roughness of the resin nano ceramic group.

\section{INTRODUCTION}

The success of ceramic restorations and the advancements achieved in the development of improved dental ceramic systems have played a role in the increased popularity of and the shift towards these systems. ${ }^{[1,2]}$ Dental ceramics are known for their excellent aesthetics and biocompatibility. ${ }^{[3,4]}$ They have shown the most accurate reproduction of the appearance, color, and texture of natural teeth. ${ }^{[5,6]}$

Zirconia-based ceramics are among the most popular and the most widely used ceramics in the modern dental practice..$^{[7,8]}$ This can be attributed to their superior mechanical properties ${ }^{[7-10]}$ and excellent biocompatibility ${ }^{[9,11-13]}$ comparable to other dental ceramics.

The stability of dental ceramics in the oral environment is directly related to the high surface polish, subcritical crack propagation, and chemical inertness of these materials, which in turn enables them to resist degradation in the oral environment. ${ }^{[2]}$ Surface roughness will jeopardize the biomechanical and esthetic value of a dental restoration, increasing its susceptibility to aging. ${ }^{[14]}$ A rough-surfaced dental restoration will not only favor more plaque retention ${ }^{[15]}$ and cause abrasive damage to opposing dentition, ${ }^{[16-19]}$ but will also be weakened by the presence of these surface flaws that can, very often, be the starting point of material failure. ${ }^{[20]}$

The idea of combining ceramic with resin has always been an attractive idea. Combining the strength and color stability of ceramic with the resilience of resin decreases forces transmitted to underlying structures and decreases wear. This has led to the introduction of nano-hybrid ceramics. Lava Ultimate is a resin nano-ceramic material that holds a unique chemical composition consisting of $80 \%$ (by weight) nanoceramic particles of zirconia, silica, and zirconia/silica cluster agglomerates which are bound in the resin matrix. It is possible that the chemical composition of the material and its resin content play a role in the way the material reacts to the accelerated aging process. The resin matrix, as a polymer-based substance, may undergo surface degradation and roughening as a result of clinical service ${ }^{[21]}$ or due to artificial accelerated aging with UV-light-weathering. ${ }^{[22]}$ The initial color match and color stability are crucial determining factors for both initial and the long-term esthetic success of a dental restoration. ${ }^{[23-25]}$ However, the optimal match of a ceramic restoration to natural teeth depends not only on the color and translucency, but also depends on color changes which occur over time as the material ages. ${ }^{[5,23]}$ Color shifting in dental restorative materials may occur over time,,$^{[25]}$ hence, color stability arises as key to the long-term aesthetic success of dental restoration. ${ }^{[23-25]}$

Artificial accelerated aging is an experimental method used to simulate oral environmental conditions extra-orally. ${ }^{[3,23,26]}$ A weathering process that involves exposure to ultraviolet light, fluctuant temperatures, and variable humidity has been used to artificially age prosthetic materials. ${ }^{[3,26]}$

The purpose of the study was to evaluate the effects of artificial accelerated aging on surface roughness and color stability of three ceramic materials. The hypothesis was that artificial accelerated aging will have an effect on the surface roughness and color stability of tested ceramic materials.

\section{METHODS}

A total of 21 disc-shaped specimens $(2 \mathrm{~mm}$ thick and $10 \mathrm{~mm}$ in diameter) were fabricated for use in the study, divided equally into 3 groups $(n=7)$. These consisted of two different sets of monolithic discs and a set of bi-layered ceramic discs. Translucent zirconia ceramic blocks for CAD/CAM (inCoris TZI) were used for fabrication of the first set of monolithic discs (Group $T$ ), whereas resin nano-ceramic blocks for CAD/CAM (Lava Ultimate) were used for fabrication of the second set of monolithic discs (Group L). In addition, zirconia ceramic blocks for CAD/CAM (inCoris $\mathrm{ZI}$ ) were used for the fabrication of $1 \mathrm{~mm}$ thick zirconia substructures (with a diameter of $10 \mathrm{~mm}$ ) which were veneered by VM9 feldspathic porcelain using a traditional hand 


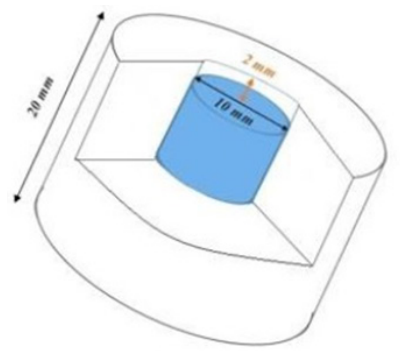

A

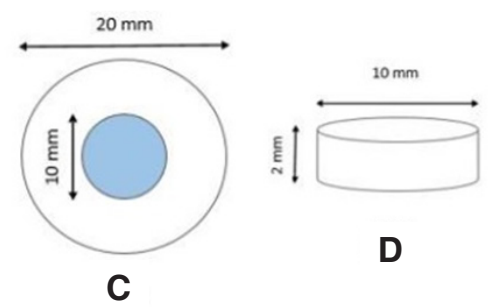

Figure 1: Schematic diagrams. (A) General view of the teflon mold constructed for specimen fabrication; (B): longitudinal section in the mold; (C): cross section of the mold; (D): a monolithic disc; (E) a bilayered disc

layering technique to obtain bi-layered ceramic discs (Group F).

The CerecinLab MC XL was used for CAD/CAM fabrication of all specimens by fabricating 2 molds for the construction of the disc-shaped specimens. Each mold was constructed from dense Teflon in 2 parts, including a cylinder with a height of $20 \mathrm{~mm}$, external diameter of $20 \mathrm{~mm}$ and an internal diameter of $10 \mathrm{~mm}$, and a piston that fit tightly into this internal diameter [Figure 1]. When the piston was completely seated within the cylinder (placed flush on a flat surface) it was $2 \mathrm{~mm}$ shorter than the cylinder walls for the first mold, and $1 \mathrm{~mm}$ shorter for the second mold. In effect, this created a disc-shaped space with the dimensions of $10 \mathrm{~mm}$ in diameter $\times 2 \mathrm{~mm}$ in depth or $1 \mathrm{~mm}$ in depth, depending on the mold.

The mold with the $2 \mathrm{~mm} \times 10 \mathrm{~mm}$ space was used for the fabrication of monolithic discs, while the mold with the $1 \mathrm{~mm} \times 10 \mathrm{~mm}$ space was used for the fabrication of zirconia substructures that were later placed in the first mold occupying the bottom $1 \mathrm{~mm}$ of the $2 \mathrm{~mm}$ deep space. This left the superior $1 \mathrm{~mm}$ open for the veneering VM9 feldspathic porcelain which was done using a traditional hand layering technique.

The thickness of each disc-shaped specimen was confirmed to be $2.0 \pm 0.1 \mathrm{~mm}$ using a digital caliper. Group $\mathrm{T}$ and group $\mathrm{F}$ specimens underwent further glazing whereas group $\mathrm{L}$ specimens underwent polishing only according to the manufacturer's instructions. All specimenswere then cleaned ultrasonically in a distilled water bath for $10 \mathrm{~min}$, compressed-air-dried, and stored clean and dry in a dark environment until the time of measurement.

Color measurements in the current study were done prior to accelerated aging using a spectroradiometer (PR 705; Photo Research Inc., Chatsworth, California) and fiber optic light cable fixed to an optical table (Mecomlnc., Risingsun, Ohio). The fiber optic light cable was connected to a xenon arc lamp (300 W; Newport Corp-Oriel Instruments, Stratford, Conn). The spectroradiometer and the optic light cable, positioned at a 45-degree angle inferior to the horizontal plane, provided an optical configuration of 0 -degrees of observation and 45-degrees of illumination to the object. For all color measurements in this study, spectral reflectance was obtained from 380 to 780 $\mathrm{nm}$ with a 2-nm interval (SpectraWin 2.0; Photo Research Inc.) and subsequently converted to CIELAB values (D65 illumination and 2-degree observer). The spectroradiometer was standardized to $8 \mathrm{~cm}$ to the measured object with a measurement aperture size of $1 \mathrm{~mm}$.

The surface roughness profile of each disc was registered using a profilometer (SURFTEST-SV-600 s 178 Surface Roughness Tester, MITUTOYO, Co, Santo Amaro, São Paulo, Brazil) with a cut-off value of $0.25 \mathrm{~mm}$. Three different regions were evaluated in each specimen to determine $3 \mathrm{Ra}$ values and the final value to characterize each specimen was the arithmetic mean among them. Data of this initial surface roughness profile registration were recorded as Ra1 (Surface roughness prior to artificial accelerated aging).

All specimens were aged in an accelerated aging chamber (Atlas Ci35A Xenon ${ }^{\circledR}$ Weather-O-meter, Atlas Material Testing Technology LLC, Chicago, IL, USA) set to standard CAM 180 cycles. One surface of each specimen was exposed to a controlled irradiance xenon arc filtered through borate borosilicate glass at $0.55 \mathrm{~W} / \mathrm{m}^{2}$ at $340 \mathrm{~nm}$, a black panel temperature of $70{ }^{\circ} \mathrm{C}$ (light cycle) and $38{ }^{\circ} \mathrm{C}$ (dark cycle), a dry bulb temperature of $47{ }^{\circ} \mathrm{C}$ (light cycle) and $38{ }^{\circ} \mathrm{C}$ (dark cycle), and a humidity of $50 \%$ (light cycle) and $95 \%$ (dark cycle). The test cycle was 40 min light only, 20 min light plus front water spray, $60 \mathrm{~min}$ light only, and $60 \mathrm{~min}$ dark plus back water spray. A total energy of $450 \mathrm{~kJ} / \mathrm{m}^{2}$ was conducted over the entire weathering process. All specimens underwent the same color and surface roughness measurements after the accelerated aging process.

The color difference $(\Delta E)$ values were evaluated by calculating the difference in color measurements of the specimens before and after artificial accelerated aging 
Table 1: Comparative statistics of Wilcoxon Signed Rank Test, mean values \pm SD of surface roughness (in $\mu$ m) before aging, after aging and the difference between three ceramic groups

\begin{tabular}{lcccc}
\hline Ceramic group & Before aging & After aging & Difference & $P$ value \\
\hline Group F & $2.5386 \pm 1.25783$ & $2.8795 \pm 0.70405$ & $0.3409 \pm 1.21466$ & 0.398 \\
Group L & $0.9371 \pm 0.33515$ & $0.6219 \pm 0.28367$ & $-0.3152 \pm 0.35781$ & $0.028^{*}$ \\
Group T & $0.3600 \pm 0.06880$ & $0.9738 \pm 0.39798$ & $0.6138 \pm 0.40545$ & 0.499 \\
\hline
\end{tabular}

*Statistically significant difference $(P<0.05)$

by using the following formula $\Delta E\left(L^{*} a^{*} b^{*}\right)=\left[\left(L^{*} 1-\right.\right.$ $\left.\left.L^{*} 2\right)^{2}+\left(a^{*} 1-a^{*} 2\right)^{2}+\left(b^{*} 1-b^{*} 2\right)^{2}\right]^{1 / 2}$, where numbers "1" and " 2 " refer to the color coordinates before and after artificial accelerated aging, respectively. The amount of surface roughness change was calculated for each specimen as $R a=R a 2-R a 1$, where Ra1 is the arithmetic mean roughness before aging and Ra2 is the arithmetic mean roughness after aging.

At a sample size of $n=7$ and significance level of $\alpha=$ 0.05 , the statistical power value of the current study was 0.936 . Power analysis was done using $\mathrm{G}^{*}$ Power test (Version 3.1.9.2).

Values were presented as means \pm standard deviation (SD) at a 95\% confidence interval with a " $P$ value" of $5 \%$ as the limit of statistical significance. The effect of artificial accelerated aging on surface roughness of each individual ceramic group was statistically analyzed using the Wilcoxon Signed Rank test.

\section{RESULTS}

The test results revealed that only group $L$ specimens (Lava Ultimate ceramic) showed a statistically significant difference in surface roughness before and after artificial accelerated aging $(P=0.028)$. There was no statistical significance in surface roughness in both the $\mathrm{T}$ group $(P=0.499)$ and the $\mathrm{F}$ group $(P=0.398)$ before and after aging [Table 1].

With regards to color stability, the amount of color change $(\triangle \mathrm{E})$ was calculated using the CIELAB formula. The means of $\triangle \mathrm{E}$ values of the 3 ceramic groups were $\Delta \mathrm{E}^{*}=0.8743 \pm 0.32837$ for the T group, $\Delta \mathrm{E}^{*}=2.29 \pm$ 0.49866 for the $\mathrm{L}$ group, and $\Delta \mathrm{E}^{*}=0.8514 \pm 0.46763$ for the $F$ group.

\section{DISCUSSION}

The first hypothesis that artificial accelerated aging has an effect on the surface roughness of tested ceramic materials was accepted. There was a statistically significant difference in surface roughness of the $L$ group (Lava Ultimate ceramic) $(P=0.028)$ before and after aging, which supported the hypothesis. However, accelerated aging did not have an effect on surface roughness of the other 2 groups of ceramics. Lee et al. ${ }^{[22]}$ reported that after accelerated aging under xenon light and $90 \%$ relative humidity, the matrices of resin eroded, and as a result, the resin showed a chalky surface with increased surface roughness. However, this finding contradicted those of the current study; although a significant change in surface roughness of group $L$ ceramics was observed, surface roughness decreased after artificial aging.

As zirconia ages, grain pull-out is reported as a sequela of the proposed aging process, with subsequent adverse effects on the surface finish and optical properties of these restorations. The surface roughness of materials may adversely influence their optical properties. ${ }^{[27,28]}$ However, this was not shown by the results of this study. The other two groups, group $T$ and group $F$, were not affected by the accelerated aging process, and the suggested sequela could not be confirmed.

The second hypothesis that artificial accelerated aging has a significant effect on the color stability of the three ceramic materials was rejected. With regards to color stability of tested ceramic materials, the perceptibility level set in this study was $2 \Delta \mathrm{E}$ units, whereas the clinical acceptability level was set to $3.7 \Delta \mathrm{E}$ units, as determined by many studies. ${ }^{[21,29,30]}$ The 3 ceramic groups showed clinically acceptable color stability after $300 \mathrm{~h}$ of artificial accelerated aging, with the largest amount of color change observed in the $L$ group, with a mean of $2.29 \Delta \mathrm{E}$ units. The lowest amount of color change was observed in the $\mathrm{F}$ group, with a mean of $0.85 \Delta \mathrm{E}$ units, while the T group was in the middle with a mean of $0.87 \Delta \mathrm{E}$ units. However, the amount of color change in ceramics of the $L$ group was above the level of perceptibility, indicating that it was perceivable to the human eye, although it was still below the level of clinical acceptability.

Artificial accelerated aging is a method which claims to simulate intraoral conditions. The manufacturer claims that $300 \mathrm{~h}$ of weathering in a weather-O-meter equals one year of clinical service intraorally. However, there are no data to support this claim. ${ }^{[21]}$ Many studies have used this weathering process to test various dental restorative materials for color stability and surface roughness, including dental composites, 
resin cements, and dental ceramics. ${ }^{[3,21,26,31]}$ However, use of this method to test performance and endurance of dental restorative materials in vitro is convenient and provides us with more realistic expectations of the long-term outcome of these restorations. ${ }^{[4,21]}$ The method of artificial accelerated aging used in the current study is a weathering process marked as CAM 180. This method, as proposed by ASTM G155, is one of several cycles used for operating xenon-arc light apparatus for exposure of nonmetallic materials. It encompasses alternate exposures of darkness and light as well as intermittent exposure to a water spray. Validation of this method has been verified by previous studies. ${ }^{[21,26,31]}$ It is unclear as to how many hours in an artificial accelerated aging instrument are equal to one year of clinical service. There is no established answer to this question in the literature. However, the manufacturer of the artificial aging chamber claims that $300 \mathrm{~h}$ in the weathering chamber is equivalent to one year of clinical service. ${ }^{[3,21,26,31]}$ It has been suggested that color change caused by artificial accelerated aging involving UV irradiation is related to the internal color stability of the material itself, i.e. intrinsic factors within the material, ${ }^{[22]}$ and occurs within $300 \mathrm{~h}$ of accelerated aging. ${ }^{[3,21,31]}$

In the current study, group L specimens (Lava Ultimate ceramic) showed the greatest amount of color change with a $\Delta \mathrm{E}^{*}$ value of 2.28. Although the amount of color change in group $\mathrm{L}$ is still within the limit of clinical acceptability, it surpassed the level of perceptibility and showed the largest color shift among the 3 groups. The different structuring of the Lava Ultimate ceramic may have influenced the amount of change in color caused by artificial accelerated aging. The resin content of these ceramic blocks, although highly converted and cross-linked and fully cured, may have undergone chemical disassociation which triggered the intrinsic color shift. This pattern of chemical dissociation is claimed to be the way this method of artificial aging affects resinous substances. ${ }^{[4,21]}$ In the other 2 ceramic groups, a slight and insignificant color change took place as a sequela to the artificial accelerated aging. The amount of color change observed in the $F$ and $\mathrm{T}$ groups was insignificant, and was below both the clinical acceptability and perceptibility levels set in this study. The slight color change observed in these 2 groups may be due to breakdown of the metal oxide content of the colorants added to the ceramic itself, or due to the ceramic coloring liquid used to give the ceramic its appropriate shade match. The breakdown of metal oxides under ultraviolet radiation is followed by peroxide compound formation that would likely change the color of the shaded ceramic material. ${ }^{[3]}$ Another potential cause of the difference in the amount of color change between the specimens is the difference in the fabrication procedure that was followed in this study, in accordance with the manufacturers' recommendations for each of the 3 groups. Per the manufacturer for Lava Ultimate, ceramic restorations should only be polished and are ready to be delivered. This is believed to be due to the high resin content which may be damaged by the high sintering and glazing temperatures. The zirconia polycrystals in these ceramic blocks are fully sintered. In contrast, the manufacturers' recommendations for the other 2 groups involved further sintering and glazing to give the material its final strength and characterization. Although polishing has been studied previously, and was proposed as a convenient method for producing surface smoothness comparable to that produced by glazing, researchers have continued to investigate the differences between polishing and glazing of dental ceramics.

Although laboratory surface roughness and color stability values after artificial accelerated aging may not reflect intraoral conditions, these values are nevertheless helpful in comparing materials under controlled situations and may be a helpful predictor of clinical performance. Further studies on Lava Ultimate resin nano ceramics are needed to investigate their performance and their ability to survive oral environmental conditions. Prolonged aging periods may be needed.

In conclusion, within the limitations of the current study it can be concluded that: (1) Bi-layered zirconiabased restorations (inCoris $\mathrm{ZI}$ substructure with VM9 feldspathic veneering) and monolithic zirconiabased restorations (inCoris TZI) showed clinically acceptable surface roughness and color stability after being subjected to artificial accelerated aging; (2) artificial accelerated aging significantly affects surface roughness of resin nano ceramic (Lava Ultimate ceramic), while it does not affect its color stability.

\section{Financial support and sponsorship}

None.

\section{Conflicts of interest}

There are no conflicts of interest.

\section{Patient consent}

Not applicable.

\section{Ethics approval}

Not applicable.

\section{REFERENCES}

1. Conrad HJ, Seong WJ, Pesun IJ. Current ceramic materials and systems with clinical recommendations: a systematic review. J Prosthet Dent 
2007;98:389-404.

2. Raigrodski AJ. Contemporary materials and technologies for allceramic fixed partial dentures: a review of the literature. J Prosthet Dent 2004;92:557-62.

3. Pires-de-Souza Fde C, Casemiro LA, Garcia Lda F, Cruvinel DR. Color stability of dental ceramics submitted to accelerated aging after repeated firings. J Prosthet Dent 2009;101:13-8.

4. Nikzad S, Azari A, Poursina M. Effects of beverage colorants and accelerated aging on the color stability of indirect resin composites. $J$ Dent Sci 2012;7:231-7.

5. Singh K, Suvarna S, Agnihotri Y, Sahoo S, Kumar P. Color stability of aesthetic restorative materials after exposure to commonly consumed beverages: a systematic review of literature. Eur J Prosthodont 2014;2:15-22.

6. Vichi A, Louca C, Corciolani G, Ferrari M. Color related to ceramic and zirconia restorations: a review. Dent Mater 2011;27:97-108.

7. Liu MC, Aquilino SA, Gratton DG, Ou KL, Lin CC. Relative translucency and surface roughness of four yttrium stabilized tetragonal zirconia polycrystalline-based dental restorations. $J$ Exp Clin Med 2013;5:22-4.

8. Giordano R. Materials for chairside CAD/CAM-produced restorations. J Am Dent Assoc 2006;137 Suppl:S14-21.

9. Ardlin BI. Transformation-toughened zirconia for dental inlays, crowns and bridges: chemical stability and effect of low temperature aging on flexural strength and surface structure. Dent Mater 2002;18:590-5.

10. Denry I, Kelly JR. State of the art of zirconia for dental applications. Dent Mater 2008;24:299-307.

11. Flinn BD, deGroot DA, Mancl LA, Raigrodski AJ. Accelerated aging characteristics of three yttria-stabilized tetragonal zirconia polycrystalline dental materials. J Prosthet Dent 2012;108:223-30.

12. Saridag S, Tak O, Alniacik G. Basic properties and types of zirconia: an overview. World J Stomatol 2013;20:40-7.

13. Wang L, Liu Y, Si W, Feng H, Tao Y, Ma Z. Friction and wear behaviours of dental ceramics against natural tooth enamel. J Eur Cer Soc 2012;32:2599-606.

14. Volpato CM, Garbelotto LD, Fredel MC, Bondioli F. Application of zirconia in dentistry: biological, mechanical and optical considerations. In: Sikalidis C, editors. Advances in ceramics - electric and magnetic ceramics, bioceramics, ceramics and environment. Rijeka: InTech; 2011. p. 399-419.

15. Oliveira-Junior OB, Buso L, Fujiy FH, Lombardo GH, Campos F, Sarmento HR, Souza RO. Influence of polishing procedures on the surface roughness of dental ceramics made by different techniques. Gen Dent 2013;61:e4-8.
16. Al-Shammery HA, Bubb NL, Youngson CC, Fasbinder DJ, and Wood DJ. The use of confocal microscopy to assess surface roughness of two milled CAD-CAM ceramics following two polishing techniques. Dent Mater 2007;23:736-41.

17. al-Wahadni A, Martin DM. Glazing and finishing dental porcelain: a literature review. J Can Dent Assoc 1998;64:580-3.

18. Rashid H. Evaluation of the surface roughness of a standard abraded dental porcelain following different polishing techniques. J Dent Sci 2012;7:184-9.

19. Beuer F, Stimmelmayr M, Gueth JF, Edelhoff D, Naumann M. In vitro performance of full-contour zirconia single crowns. Dent Mater 2012;28:449-56

20. Lohbauer U, Muller FA, Petschelt A. Influence of surface roughness on mechanical strength of resin composite versus glass ceramic materials. Dent Mater 2008;24:250-6.

21. Paravina RD, Ontiveros JC, Powers JM. Accelerated aging effects on color and translucency of bleaching-shade composites. J Esthet Restor Dent 2004;16:117-26.

22. Lee YK, Lu H, Powers JM. Changes in opalescence and fluorescence properties of resin composites after accelerated aging. Dent Mater 2006;22:653-60

23. Atay A, Oruc S, Ozen J, Sipahi C. Effect of accelerated aging on the color stability of feldspathic ceramic treated with various surface treatments. Quintessence Int 2008;39:603-9.

24. Hekimoglu C, Anil N, Etikan I. Effect of accelerated aging on the color stability of cemented laminate veneers. Int $J$ Prosthodont 2000;13:29-33.

25. Chu SJ, Trushkowsky RD, Paravina RD. Dental color matching instruments and systems. Review of clinical and research aspects. $J$ Dent 2010;38 Suppl 2:e2-16.

26. Turgut S, Bagis B. Color stability of laminate veneers: an in vitro study. J Dent 2011;39 Suppl 3:e57-64.

27. Lughi V, Sergo V. Low temperature degradation -aging- of zirconia: a critical review of the relevant aspects in dentistry. Dent Mater 2010;26:807-20

28. Cattani-Lorente M, Scherrer SS, Ammann P, Jobin M, Wiskot HW. Low temperature degradation of a Y-TZP dental ceramic. Acta Biomater 2011;7:858-65.

29. Johnston WM, Kao EC. Assessment of appearance match by visual observation and clinical colorimetry. J Dent Res 1989;68:819-22.

30. Sakai M. The optical effect of zirconia background, ceramic thickness and cement on all-ceramic material [dissertation]. Chicago: University of Illinois; 2012

31. Heydecke G, Zhang F, Razzoog ME. In vitro color stability of doublelayer veneers after accelerated aging. J Prosthet Dent 2001;85:551-7. 